\title{
CARACTERÍSTICAS ESTRUTURAIS DO DUPLEX DE JUATAMA (CEARÁ - BRASIL)
}

\author{
ANGELA L.A. MORAIS*, JOAQUIM R. TORQUATO** e MICHEL H. ARTHAUD**
}

\begin{abstract}
STRUCTURAL CHARACTERISTICS OF THE JUATAMA DUPLEX (CEARÁ BRAZIL). Among several ductile shear zones which occur in central State of Ceará, two of them have been chosen to be described in this paper. The Quixeramobim and Senador Pompeu shear zones (NE-SW) are respectively the northern and southern boundaries of the Juatama Duplex. The Juatama Duplex lies southwards from Quixadá and represents a tipical cognate conctractional directional duplex. This paper decribes the deformational events and interprets the structural characteristics of such a framework. The Fry and Center-to-Center methods have been used to investigate the deformation of the Juatama Duplex.The diagrams show that the main displacement of the duplex is dextral. The mean $2.02 \pm 0.19$ : and $1.71 \pm 0.03: 1$ respectively for the XY and XZ plans. It shows that the use of mean values is inadequate to define the total deformation.
\end{abstract}

Keywords: Structural geology, deformation, duplex, Fry method, Ceará, Brazil.

\begin{abstract}
RESUMO Na região central do Ceará ocorrem várias zonas de cisalhamento dúctil com direção aproximada NESW. Duas delas têm sido objeto de estudos pelo DEGEO/UFC: são as Zonas de Cisalhamento Dúctil de Quixeramobim e Senador Pompeu. Ligando as duas zonas, aparece, na região de Juatama (sul de Quixadá), um duplex direcional do tipo contracional cognato. Neste trabalho, apresenta-se a quantificação da deformação que as rochas daquela região sofreram e algumas características estruturais do duplex. Os métodos utilizados para o estudo da deformação foram os de Fry e Centro-a-Centro. Por meio de várias observações, foi definido um deslocamento dextral para as rochas que balizam o Duplex de Juatama e uma deformação variável, mas de valores médios da ordem de 2,02 \pm 0,19:1 e 1,71 \pm $0,03: 1$, respectivamente para os planos XY e XZ. Conclui-se que estes valores médios não podem ser usados para definir a deformação total, pois eles, embora pouco, variam de local para local. No trabalho, apresentam-se ainda os valores locais de deformação e a sua posição espacial.
\end{abstract}

Palavras-chaves: Geologia estrutural, deformação, duplex, método Fry, Ceará, Brasil.

INTRODUÇÃO A região de Juatama tem sido estudada pelos pesquisadores do Departamento de Geologia da Universidade Federal do Ceará desde 1987, quando da implantação do projeto "Granitóides do Ceará - Região de Quixadá/ Solonópole". As rochas que compõem a área em estudo fazem parte do embasamento regional e do Complexo Granítico de Quixadá-Quixeramobim, apresentado pela primeira vez, sob esta designação, por Arthaud et al (1987). Este complexo está localizado a cerca de $200 \mathrm{~km}$ ao sul de Fortaleza e mostra-se sob a forma de uma elipse irregular de eixo maior com mais de $100 \mathrm{~km}$ de comprimento, orientada NNE-SSW. A leste e oeste, está parcialmente limitado por duas grandes zonas de cisalhamento dúctil chamadas, respectivamente, de Senador Pompeu e Quixeramobim.

A área abrangida por este estudo situa-se na parte norte do complexo, entre as coordenadas de $05^{\circ} 06^{\prime} 30^{\prime \prime}$ e $05^{\circ} 10^{\prime} 00^{\prime \prime}$ de latitude Sul e $38^{\circ} 47^{\prime} 04^{\prime \prime}$ e $39^{\circ} 06^{\prime} 35^{\prime \prime}$ de longitude Oeste. Ocupa uma extensão de cerca de $350 \mathrm{~km}^{2}$ (Fig. 1).

Este trabalho visa determinar a deformação dos corpos graníticos na região de Juatama, uma vez que ali quase se tocam duas das principais Zonas de Cisalhamento Dúctil que cortam o Ceará. O seu conhecimento trará uma contribuição importante ao estudo das deformações no Nordeste; pois, pela sua situação espacial, é possível que na região em estudo se encontrem alguns dos maiores valores regionais associados a tais estruturas.

O DUPLEX DE JUATAMA A área estudada, região do Duplex de Juatama, ocupa parte da terminação norte do Complexo Granítico de Quixadá - Quixeramobim. De acordo com Sidrim et al (1988) e Torquato et al (1989), esta região é ocupada por granitóides das fácies Unique, Serra Branca, Muxuré Novo, Quixadá e Muxuré Velho, esta última exclusivamente sob a forma filoneama e pelas suas encaixantes metamórficas essencialmente paraderivadas.
A idade do conjunto é ainda uma questão em aberto. Estudos em andamento indicam que o Complexo Granítico deve ter-se posicionado há $650 \mathrm{Ma}$ e que as rochas das encaixantes parecem ser do Proterozóico Inferior.

A seqüência metamórfica paraderivada é constituída principalmente por xistos, gnaisses e quartzitos. Na região nordeste de Juatama, este conjunto encontra-se arrasado e sem afloramentos, o que impediu estender até lá o estudo da quantificação da deformação do Duplex de Juatama.

O Complexo Granítico de Quixadá-Quixeramobim é um conjunto polintrusivo, híbrido, constituído por um número considerável de corpos diferenciados e diques sin-plutônicos posicionados concordantemente às rochas hospedeiras (Torquato et al 1989). São granitóides profundos com posicionamento cinemático precoce em relação à movimentação das zonas de cisalhamento dúcteis que o margeiam (Arthaud et al 1988).

Entre as fácies presentes, só as de Muxuré Novo e Serra Branca serviram para análise deformacional. Os granitóides Muxuré Novo ocupam uma faixa NE-SW da região mapeada e pequenos corpos dispersos, um dos quais se situa precisamente sob Juatama. São rochas porfiróides com fenocristais de feldspato potássico de até $6 \mathrm{~cm}$ de comprimento. Apresentam uma associação litológica característica das séries cálcio-alcalinas com granodioritos, tonalitos, quartzo-monzonitos e quartzo-monzodioritos.

As rochas Serra Branca limitam-se à porção sudoeste de Juatama onde são marcadas principalmente pelo inselberg da Serra da Independência, assim como pequenas intrusões na fácies Muxuré Novo. A sua principal característica é a de apresentar grandes megacristais de feldspato potássico de até $20 \mathrm{~cm}$ de comprimento. Estes megacristais são, na maioria, euédricos e subédricos, zonados, por vezes quebrados e rotacionados ou com sombras de pressão assimétricas bem desenvol- 


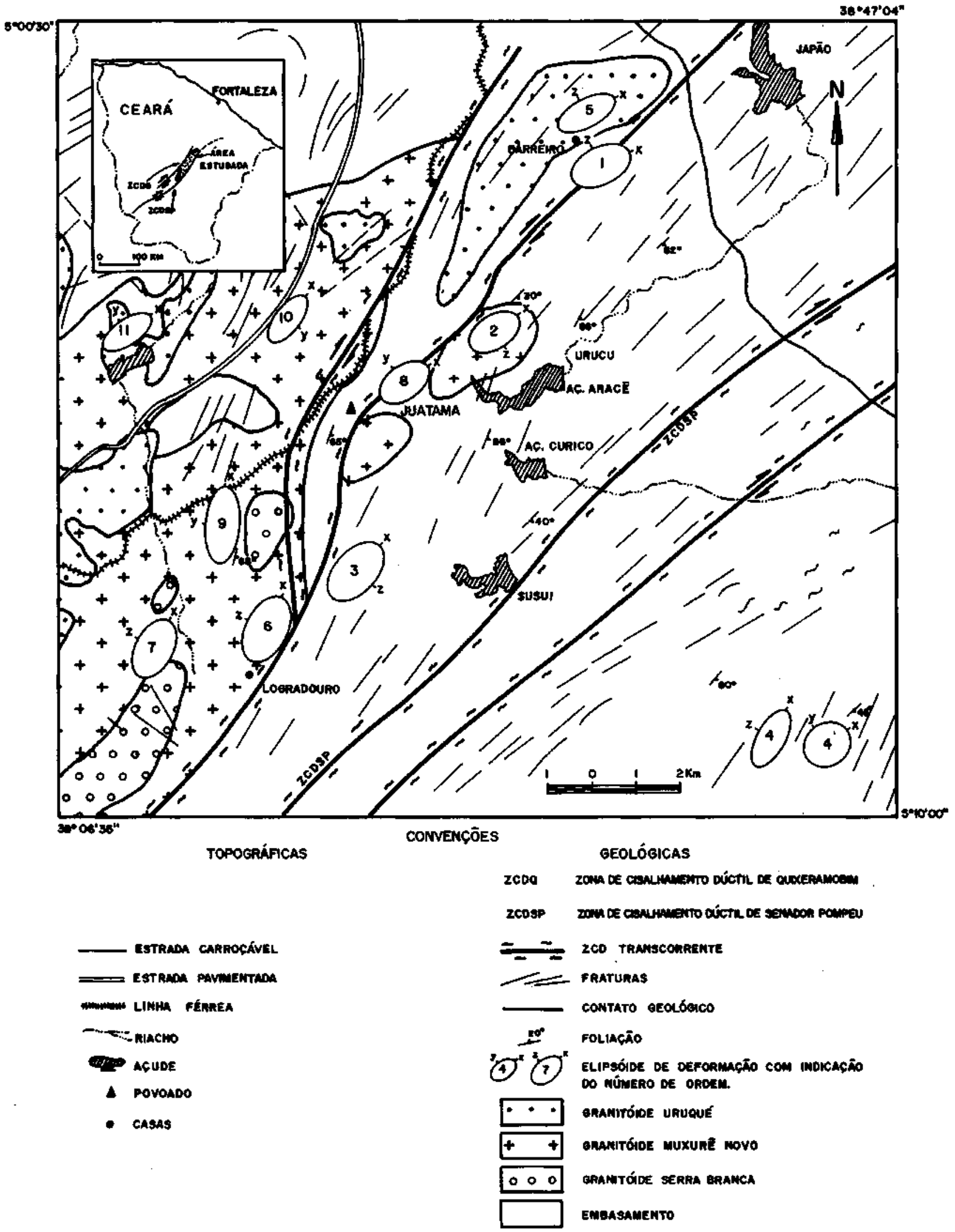

Figura 1-Mapa geológico da região de Juatama com a localização e valor em escala das elipses de deformação Figure 1 - Geologic map of the Juatama region 
vidas. Os seus litótipos são granodioritos, granites 3B, quartzomonzodioritos e tonalitos.

O Duplex de Juatama é o resultado da dissipação dos esforços das duas zonas de cisalhamento dúctil que o margeiam. É um duplex direcional, do tipo contracional, de acordo com os conceitos de Boyer \& Elliott (1982). Uma vez que as rochas que o formam são iguais às que o rodeiam, pode ser considerado como contracional cognato. $\mathrm{O}$ seu desenvolvimento terminou quando cessaram as tensões relativas aos esforços de deslocamento das zonas de cisalhamento a que está associado.

A sul, o duplex começa a individualizar-se próximo à $\mathrm{Fa}$ zenda Logradouro (cerca de $10 \mathrm{~km}$ ao sul de Juatama), saindo assintoticamente da zona de cisalhamento dúctil de Senador Pompeu que, localmente, se mostra com direção N50 ${ }^{\circ} \mathrm{E}$. Cerca de $6 \mathrm{~km}$ a sudoeste de Juatama, inicia-se uma faixa fortemente milonitizada com foliação subvertical quase N-S, direção esta que, lentamente, encurva-se para NE, chegando a Juatama com N20 E. Esta atitude mantém-se até perder-se sob a região arrasada dos gnaisses do embasamento. Reaparece ao norte da estrada que liga Quixadá a Fortaleza onde, uma vez mais, de forma assintótica, liga-se à zona de cisalhamento dúctil de Quixeramobim que, regionalmente, apresenta a direção N $50^{\circ}$ E (paralela à ZCD de Senador Pompeu).

A figura 1 mostra a metade sul do Duplex de Juatama com o posicionamento orientado das elipses de deformação. A metade norte, devido à falta de afloramentos, não foi investigada.

ANÁLISE CINEMÁTICA DA DEFORMAÇ̃̃o Para se executar o estudo da deformação regional foram escolhidos os granitóides das fácies Muxuré Novo e Serra Branca por apresentarem megacristais dispersos numa matriz relativamente fina e pelas suas magníficas exposições. Nos dois casos, devido aos processos erosivos locais, só o plano XZ do elipsóide de deformação finita é bem observado, confundindo-se, na maioria das vezes com a superfície do terreno. Marcadores de deformação, tais como foliacão, encraves, fenocristais fraturados e deslocados, sombras de pressão assimétricas, estruturas boudinadas e foliações S/C são bem evidentes nesse plano.

As características mecânicas dos granitóides estudados são bastante semelhantes, permitindo uma análise cinemática do duplex em conjunto.

O plano XY só pode ser observado em raros matacões. Quando tal acontece, aparece uma lineação de estiramento formada preferencialmente por quartzo e feldspato, com postura horizontal ou suborizontal inclusa em foliação de até $30^{\circ}$, mergulhando ora para NE ora para SW.

A foliação dos granitóides da região de Juatama é milonítica, marcada por alternância de faixas milimétricas a decimétricas, com acentuado estiramento mineral, com faixas de idêntica espessura onde a deformação foi menos intensa ou mesmo ausente. A presença de minerais máficos orientados em todas as zonas de cisalhamento dúcteis regionais, até mesmo nas de pequena expressão como a de Juatama, torna a foliação uma característica bem marcante. Segundo Arthaud et al. (1988) esta foliação foi formada em condições dúcteis, evidenciadas pelos cristais de quartzo lenticulares fortemente estirados (plasticidade cristalina associada a uma recristalização dinâmica).

Freqüentes encraves elípticos são importantes para o estudo da foliação e deformação plástica nestas zonas de cisalhamento. Localmente, apresentam deformacão de até 15:1. São constituídos de fragmentos de rochas básicas cogenéticas, intensamente foliadas e com eixo maior paralelo à direção X. Isto corrobora uma intensa deformação plástica destes granitóides.

Em Juatama e, pouco a norte, ao longo do caminho carroçável que bordeja a estrada de ferro para Quixadá, os inúmeros fenocristais de feldspato potássico losangulares rotacionados, paralelamente à direção $\mathrm{X}$, evidenciam um movimento predominantemente dextral. Contudo, em outros locais, como ao lado da Igreja de Juatama, é comum os cristais deformados indicarem uma rotação inversa, o que mostra a importância da análise cinemática dos tectonitos ser feita com base estatística.

$\mathrm{Na}$ estrada de Juatama e a sudoeste, os afloramentos do Granito Serra Branca mostram megacristais fraturados, fraturas estas que fazem um pequeno ângulo em relação ao eixo $\mathrm{X}$ do elipsóide de deformação e que, de acordo com Arthaud et al (1987), indicam movimento sintético em relação ao deslocamento ao longo da zona de cisalhamento, como também o mostram as sombras de pressão assimétricas das extremidades dos megacristais de feldspato potássico.

Nos gnaisses encaixantes, igualmente afetados pelo movimento, o plano XY contém, na maioria das vezes, veios boudinados com um aspecto característico at pinch and swell $\mathrm{e}$ direção do eixo $\mathrm{Y}$ de $\mathrm{S} 70^{\circ} \mathrm{E}$.

As dobras, especialmente nos ganisses e xistos, são raras e do tipo isoclinal, com plano axial variável de N10E a N30E, mergulho subvertical e eixo paralelo à direção de estiramento.

As feições microscópicas nos xistos são representadas por micas deformadas, disseminadas na matriz, formando microdobras isoclinais e kink-bands. Feições de mica-fish são comuns.

Por último, as foliações $\mathrm{S} / \mathrm{C}$ ocorrem em todos os tipos de rochas e, do mesmo modo, indicam um deslocamento dextral.

QUANTIFICAÇ̃̃o DA DEFORMAÇ̃̃o Para o estudo da quantificação da deformação, vários métodos foram aplicados; mas, devido às características estruturais dos diversos tipos de rochas, só as técnicas de Fry (Fry 1979, Lacassin \& Driessche 1983) e de Centro-a-Centro (Ramsay \& Huber 1983) se revelaram eficientes na solução do problema.

A técnica de Fry foi utilizada em estações de aproximadamente $1 \mathrm{~m}$, onde, pelas características das rochas, foi possível obter mais de uma centena de megacristais. Os pontos de referência foram os centros geométricos dos cristais. Um dos afloramentos, devido à insuficiência de fenocristais foi estudado em lâminas delgadas devidamente orientadas (indicado na Tab. 1 sob o n 4 ).

Tabela 1 - Deformações medidas

Table I -Measurements of the deformations

\begin{tabular}{c|l|c|c}
\hline \multirow{2}{*}{$\begin{array}{c}\text { Local de } \\
\text { Coleta }\end{array}$} & \multirow{2}{*}{ Granitóide } & \multicolumn{2}{|c}{ Planos Medidas } \\
\cline { 3 - 4 } & XZ & XY \\
\hline 1 & Muxuré Novo & $1,69: 1$ & - \\
\hline 2 & Muxuré Novo & $1,73: 1$ & - \\
\hline 3 & Muxuré Novo & $1,67: 1$ & - \\
\hline 4 & Muxuré Novo & $2,33: 1$ & $1,14: 1$ \\
\hline 5 & Muxuré Novo & $2,30: 1$ & - \\
\hline 6 & Serra Branca & $1,69: 1$ & - \\
\hline 7 & Serra Branca & $1,75: 1$ & - \\
\hline 8 & Muxuré Novo & - & $1,73: 1$ \\
\hline 9 & Serra Branca & - & $2,13: 1$ \\
\hline 10 & Serra Branca & - & $2,09: 1$ \\
\hline 11 & Serra Branca & - & $2,11: 1$ \\
\hline
\end{tabular}

A técnica Centro-a-Centro foi usada apenas em um afloramento da fácies Muxuré Novo, situado próximo ao povoado de Barreiro (ponto 5). Ali foi coletada uma amostra que, analisada em lâmina delgada orientada segundo o plano XZ, forneceu uma deformação de $(2,30: 1)$.

Excluídos os valores mais elevados dos pontos 4 e 5 , as médias inicialmente encontradas são de 2,02 $\pm 0,19: 1$ e $1,71 \pm 0,03: 1$, respectivamente para os planos XY e XZ. Estes valores sugerem que a deformação foi mais significativa na 
direção intermediária $(\mathrm{Y})$ do que na direção do estiramento (X). Isto é fisicamente impossível, sobretudo por que a foliação subvertical e a lineação de estiramento suborizontal não deixam dúvidas quanto à posição espacial do elipsóide de deformação nem quanto ao regime deformacional (transcorrente). A explicação desta aparente anomalia deve ser procurada pela deformação apresentar um forte componente de cisalhamento puro e se processar, portanto, no domínio do achatamento (X pouco diferente de Y). Neste caso, a média das medidas pode não ser muito significativa, tornando-se mais conveniente uma interpretação individual dos afloramentos. Infelizmente, poucos são os locais que permitem a observação de dois dos planos principais da deformação.

O ponto 4 que não permitiu a medida dos centros dos cristais no campo. Optou-se, no caso deste afloramento, por coletar uma amostra orientada e trabalhar os dados por meio de fotografias de lâminas delgadas. Foi o único ponto medido no qual se obteve localmente a quantificação total da deformação (2,33:2,04:1), confirmando um elipsóide fortemente achatado (oblato) com valor de $\mathrm{K}=0,137$, valor este compatível com uma zona de cisalhamento dúctil com forte componente de cisalhamento puro.

A deformação mais intensa observada no ponto 4 , no plano XZ, situado a leste da Zona de Cisalhamento Dúctil de Senador Pompeu, logo, sem associação aparente com o Duplex de Juatama, poderá ser explicada pelas diferentes deformações que afetaram desigualmente os dois conjuntos de rochas.

Quanto ao ponto 5, o valor mais acentuado da deformação no plano XZ pode ter sido originado pela situação espacial deste afloramento em relação às zonas de cisalhamento dúctil, uma vez que se localiza na região mais central do Duplex de Juatama, ficando assim mais sujeito às variações de movimentação da suas margens.
Anteriormente, Arthaud et al (1988) apresentaram algumas medidas da deformação das rochas do Complexo Granítico. Arthaud et al. (1988) fizeram duas medidas nos granitóides Serra Branca, uma na região mais deformada, onde a elipsidade de XZ forneceu um valor de $(2,9: 1)$ e outra, na menos deforma$\mathrm{da}$, onde encontraram um círculo perfeito $(1: 1)$. Simplício (1989) fez três medidas no plano XZ e obteve para a fácies Muxuré Novo o valor de (2,5:1) e para a fácies Serra Branca $(2,6: 1)$ por meio de duas medidas.

CONCLUSÕES Apesar do número pequeno de medidas efetuadas, pela análise dos resultados obtidos, é possível concluir que:

1. O Duplex de Juatama apresenta movimento dextral

2. A deformação do duplex mostra valores médios de $2,02 \pm$

0,19:1 segundo o plano XY e 1,71 $\pm 0,03: 1$ segundo XZ.

3. Não é possível encontrar um valor geral médio que defina em conjunto as deformações segundo XY e XZ, pois fenômenos associados, tais como a presença de um forte componente de cisalhamento puro podem ter afetado bastante o resultado final do cisalhamento dúctil (valores locais de $\mathrm{K}=0,137$ ). 4. Valores anômalos tanto podem ser encontrados em afloramentos mais afastados das ZCD como em locais onde estas passam a sofrer a ação conjunta das deformações das duas zonas de cisalhamento dúctil.

5. Os valores encontrados para a deformação segundo o plano $\mathrm{XZ}$ são totalmente independentes dos tipos litológicos afetados; os observados segundo XY parecem atingir de modo mais intenso os litótipos mais grosseiros.

Agradecimentos Um dos autores (ALAM) agradece ao CNPq pela ajuda financeira fornecida pela Bolsa de Aperfeiçoamento Tipo B, Processo 821207/88-3.

\section{REFERÊNCIAS BIBLIOGRÁFICAS}

ARTHAUD, M.H.; ALMEIDA, A.R.; ANDRADE, J.F., P; MARANHÃO, C.M.L.; NOGUEIRA, J.A., Neto; PARENTE, C.V.; SIDRIM, A.C; SOUSA, J.V.; TORQUATO, J.R.G.. 1987. A utilizacão dos critérios rotacionais em zonas de cisalhamento dúctil: o exemplo do Complexo Granítico de Quixadá-Quixeramobim/Ceará. In: SIMP. NAC. ESTUDOS TECTÔNICOS, 1. Salvador, 1987. Resumos... Salvador, SBG. p. 45-47.

ARTHAUD, M.H.; TORQUATO, J.R.; NOGUEIRA, J.A., Neto 1988. A deformação do Granito Serra Branca - Complexo Granítico de QuixadáQuixeramobim. In: CONGR. BRAS. GEOL., 35. Belém, 1988. Anais... Belém, SBG. v. 3, p. 1015-1023.

BOYER, S.E. \& ELLIOT, D. 1982. Thrust system. Am. Assoc. Petrol. Geol. Bull., 66:1196-1230.

FRY, N. 1979. Density distribution techniques and strained length methods for determination of finite strains. J. Strut. Geol, 1:221-229.

LACASSIN, R. \& DRIESCHE, J.V.D. 1983. Finite strain determinations of gneiss: aplications of Fry's methods to porphyroid in the Southern Massif Central - France. J. Strut. Geol. 5(3/4):245-253.

RAMSAY, J.G. \& HUBER, M.I. 1983. Modern structural geology, v. 1. In: Strain Analysis. New York, Academic Press. 307 p.
SIDRIM, A.C.G.; MARANHÃO, C.M.L.; PARENTE, C.V.: ANDRADE, J.F., P 1988. Geologia preliminar do Complexo Granítico QuixadáQuixeramobim - CE. In: CONGR. BRAS. GEOL., 35. Belém, 1988. Anais... Belém, SBG. v. 3, p. 1024-1036.

SIMPLÍCIO, M.A.R. 1989. Geologia da Região de Juatama (Folha de Quixeramobim - CE). Ceará. 112 p. (Relatório de Graduação, DEGEO/UFC).

TORQUATO, J.R.; ALMEIDA, A.R.; SIDRIM, A.C.G., MARANHÃO C.M.L.; PARENTE, C. V.; NOGUEIRA, J. A., Neto; ANDRADE, J.F., P SOUZA, J.V.; NOGUEIRA DE SOUSA, M.J.; ARTHAUD, M.H. 1989. Granitóides do Ceará - Região de Quixadá - Solonópple. Rev. Geol., 2(1,2):5-143.
MANUSCRITO A711

Recebido em 2 de novembro de 1991 Revisão do autor em 22 de maio de 1992
Revisão aceita em 27 de maio de 1992 